\title{
Sześćdziesięciolecie działalności Polskiego Towarzystwa Antropologicznego
}

\author{
Andrzej Malinowski
}

THE SIXTIETH ANNIVERSARY OF THE POLISH ANTHROPOLOGICAL SOCIETY. The history of the Polish Anthropological Society is in the major part the history of Polish anthropology. The paper discusses the development of the scientific institutions and the major activists associated with the history of the Society.

Tradycje antropologii jako samodzielnej dyscypliny biologicznej liczą niewiele ponad 200 lat. W ciągu tego okresu zgromadzono olbrzymie materialy faktograficzne, które w znacznej części uporządkowano i zamknięto w zwarte systemy uogólniające i teorie. Możliwości i ambicje tej nauki są znaczne, ale nadal bywają one niekiedy niedoceniane, zwlaszcza, jak się wydaje, w medycynie, czy nawet biologii. Jak to często ma miejsce w nauce, rozwijające się wraz z głównymi nurtami biologii XIX i XX w. liczne kierunki naukowe w antropologii nie wytrzymywaly próby czasu i upadaly, inne zaś rozwijaly się i na trwale wzbogacily wiedzę o czlowieku.

W krótkiej historii antropologii jako samodzielnej dyscypliny naukowej, antropologia polska stosunkowo wcześnie uzyskala międzynarodową pozycję i uznanie.

Instytut Antropologii UAM ul. Fredry 10, 61-701 Poznań
Jeszcze w czasie zaborów, w trudnym dla życia narodu okresie powstawaly jej ośrodki w Krakowie i w Wilnie. Niemal równocześnie na prowincji propagowali antropologię liczni przyrodnicy i lekarze podejmując cenne badania naukowe.

Trwaly fundament dla rozwoju polskiej antropologii polożyl jednak dopiero znakomity Józef Majer, który w 1856 roku podjal jej uniwersyteckie wyklady i doprowadzil do powstania w 1873 roku przy Akademii Umiejętności w Krakowie Komisji Antropologicznej. Warto owe daty przedstawic na tle powstawania naukowych organizacji antropologicznych na świecie. W 1859 r. powstalo Paryskic Towarzystwo Antropologiczne, w 1863 r. angielskie w Londynie, w 1865 r. hiszpanskie w Madrycie, w $1868 \mathrm{r}$. wloskic we Florencji, w 1869 r. niemieckie w Berlinie. w 1870 r. austriackie w Wiedniu, w 1882 r. belgijskie w Brukseli i w 1884 r. japoniskie w Tokio. 
W tym okresie polscy antropolodzy wzbogacali często również swym dorobkiem naukowym obce środowiska naukowe. Wśród nich byli zeslańcy i emigranci. Znaczna ich liczba znalazła się w drugiej polowie XIX w. w Paryżu. Gdy zorganizowano w tym mieście w $1878 \mathrm{r}$. Międzynarodową Powszechną Wystawę, do jej wspóltworzenia zostaly zaproszone również dwie polskie organizacje, a mianowicie: Towarzystwo Antropologiczne i Etnograficzne Polskie w Paryżu, oraz Towarzystwo Literacko-Historyczne. Towarzystwo Antropologiczne i Etnograficzne Polskie w Paryżu zostalo zalożone w 1878 r. na wzór Paryskiego Towarzystwa Antropologicznego (Société d'Anthropologie de Paris) [ABRAMOWICZ 1975, GODYCKI 1958]. Jako cel swej działalności przyjęlo: "badanie nauki wszystkich ludów, które mogą z jakiegokolwiek tytulu być związane $\mathrm{z}$ narodowością polską". Czlonkami Towarzystwa byli: Teofil Chudziński, Franciszek Duchiński, Waclaw Gasztowtt, Edward Goldstein, L. Gostyński, Kazimierz Gregorowicz, Izydor Kopernicki, Edward Landowski, Jan Mierzejewski, Ludwik Nabielak, Godfryd Ossowski, Walery Pietkiewicz, Zygmunt Zaborowski i Jan Zawisza.

W dniu 1 marca 1878 r. towarzystwo wydalo odezwę z powodu Wystawy Powszechnej w Paryżu, w której m.in. czytamy: "Pierwszy to raz od dawnych czasów kraj nasz na zewnątrz pod swym wlasnym wystąpi mianem. Niechże to miano, które tak żywym przez dziesięć wieków blyszczalo światlem na polu wiedzy zajaśnieje. Okażmy światu i gościnnym a szlachetnym gospodarzom Wystawy, że ojczyzna Kopernika i Śniadeckich gościnności tej godna - że istniejemy". Wedlug owej odezwy "antropologia jest nauką zajmującą się wylącznie czlowiekiem i plemionami rodu ludzkiego. Zasila się ona wiadomościami, które czerpie z różnych nauk, jak etnografia, archeologia, lingwistyka, demografia, a z których każda, stanowiąc dzial osobny ogólnej antropologicznej nauki, przynosi jej material własnymi badaniami, na właściwym sobie polu zdobyty, odnoszący się także do cech fizycznych i fizjologicznych rodu ludzkiego w ogólności, jak również do stosunków między nimi a resztą grup jestestw żyjących i ras ludzkich porównywanych między sobą wedle podobieństw i różnic".

Jak stwierdzil ABRAMOWICZ [1975], w krótkim czasie towarzystwo wykonalo olbrzymia pracę i udzial nauki polskiej w Międzynarodowej Powszechnej Wystawie w Paryżu byl sukcesem. Ekspozycja zorganizowana przez Towarzystwo Antropologiczne i Etnograficzne byla zasilona zbiorami pochodzącymi $z$ licznych regionalnych polskich towarzystw naukowych i muzeów oraz od osób prywatnych. Interesujący opis na lamach "Nowin" z 1878 r. z tej wystawy przedstawil Henryk Sienkiewicz $w$ artykule pt. "Z wystawy antropologicznej w Paryżu". Wedlug obszernej relacji znakomitego pisarza, wystawa antropologiczna byla niewątpliwie sukcesem nauki polskiej i budzila powszechne uznanie.

Inne szczególy dzialalności towarzystwa, w tym zakończenie jego dzialalności, nie sa nam znane. Wiemy tylko, że Teofil Chudziński i Edward Landowski zostali za swą dzialalność odznaczeni palmami akademickimi oraz, że honorowym prezydentem towarzystwa byl Piotr Topinard, wybitny antropolog, profesor Instytutu Antropologicznego i dyrektor Wydzialu Antropologii Powszechnej Wystawy w Paryżu. Również Z. Zaborowski napisal obszerny artykul omawiający dzialalnosć towarzystwa, a zwlaszcza Wystawę w Revue 
d'Anthropologie $\mathrm{z}$ roku 1879. Być może archiwa paryskie posiadają materialy dotyczące dzialalności tego towarzystwa.

W okresie przed pierwszą wojną światową wzrastalo zainteresowanie badaczy a także dużej części inteligencji polskiej problemami antropologii. Zyskala ona popularność w środowisku przyrodników i lekarzy, socjologów i historyków. Już wówczas powstala na Uniwersytecie Jana Kazimierza we Lwowie, Katedra Etnologii i Antropologii (1913 r.), kierownictwo której powierzono Janowi Czekanowskiemu.

Jednakże dopiero po wskrzeszeniu w 1918 roku państwa polskiego zaistnialy bardziej sprzyjające warunki dla rozwoju antropologii. W tym czasie nauki antropologiczne szeroko propagowali w spoleczeństwie m.in. Ludwik Krzywicki, Ludwik Hirszfeld, Stanislaw Poniatowski, i znaczna już wówczas liczba innych znakomitych, wyksztalconych w antropologii uczonych. Zapewnilo to dynamiczny rozwój akademickich placówek antropologicznych $\mathrm{w}$ Warszawie (K. Stolyhwo, E. Loth, J. Mydlarski), w Krakowie (J. TalkoHryncewicz, A. Wrzosek, K. Stolyhwo), w Wilnie (J. Talko-Hryncewicz, M. Reicher), we Lwowie (J. Czekanowski) i w Poznaniu (A. Wrzosek). Prężnie rozwijaly się cztery oryginalne kierunki badawcze, a mianowicie: Iwowska typologiczna szkola antropologiczna J. Czekanowskiego, warszawski kierunek anatomiczno-porównawczy części miękkich E. Lotha, morfologiczny kierunek krakowski K. Stolyhwy i porównawczo-rozwojowa biologia czlowieka A. Wrzoska w Poznaniu.

Już w 1924 roku E. Czepurkowski podkreślal wielki postęp zachodzący w polskiej antropologii. Inny wybitny rosyjski antropolog, B.I. Wiszniewski w 1928 roku przyznawal, iż z państw slowiańskich antropo- logia najbardziej reprezentowana jest w Polsce.

Rozwój i różnorodnośc kierunków badawczych antropologii, wzrost dyskusji i polemik naukowych między ośrodkami antropologicznymi, a zwlaszcza między ich liderami, stworzyl konieczność znalezienia wlaściwych ram organizacyjnych dla tej nauki. Konieczne stawało się stworzenie właściwej plaszczyzny dla stalej wymiany mysli naukowej. W tym czasie utworzony, staraniem A. Wrzoska, Zaklad Antropologii Wydzialu Lekarskiego Uniwersytetu Poznańskiego byl już miejscem, w którym prowadzono interesujące badania naukowe. Prof. Adam Wrzosek, czlowiek o dużej wiedzy ogólnej i medycznej, o uznanym autorytecie, także i umiarze naukowym, byl postacią ze wszech miar odpowiednią dla integracji środowisk i znalezienia dla polskiej antropologii formy organizacyjnej. $Z$ jego to właśnie inicjatywy w dniu 12 listopada 1925 roku, w Zakladzie Antropologii Uniwersytetu Poznańskiego odbylo się zebranie, na którym obecni podjęli uchwałę o zalożeniu Polskiego Towarzystwa Antropologicznego. Czlonkami zalożycielami byli m.in. wybitni uczeni w liczbie 19 osób: dr Michal Cwirko-Godycki, dr Maria Grossmanówna, dr Anna Gluszecka, prof. Ignacy Hoffman, prof. Wincenty Jezierski, prof. Witold Kapuściński, prof. Adam Karwowski, dr Bogdan Lipiński, dr Roman Matuszewski, stud. med. Józef Medem, dr Wlodzimierz Missiuro, prof. Leon Podlewski, dr Roman Wierzbicki, prof. Adam Wodziczko, prof. Adam Wrzosek, a nadto prof. Stefan Blachowski, prof. Antoni Jakubski, prof. Józef Kostrzewski i prof. Stanisław Runge.

Przyjęto statut zezwalający m.in. na przynależność do PTA każdemu, kto interesuje się antropologią oraz uchwalono, że organem PTA ma być Przeglqd 
Antropologiczny, redagowania i wydawania którego podjąl się A. Wrzosek. Określono, że celem PTA jest przyczynianie się do rozwoju antropologii, a środkami do tego celu sa: zebrania naukowe i popieranie wydawnictw antropologicznych. W stosunkowo krótkim czasie akces do Towarzystwa zglosili niemal wszyscy antropologowie polscy oraz zainteresowani przedstawiciele nauk pokrewnych. Do wybuchu drugiej wojny swiatowej odbylo się 13 walnych zebrań, na których prezentowano 41 referatów, glównie $\mathrm{z}$ dziedziny antropologii ontogenetycznej, pedagogicznej, psychologicznej, fizjologicznej, historycznej orazz odontologii, morfologii kości i mięśni, a także afrykanistyki.

Z inicjatywy PTA zwolano we wrześniu 1933 roku w Poznaniu pierwszy zjazd antropologów w ramach XIV Zjazdu Lekarzy i Przyrodników Polskich. Siedzibą wladz $i$ redakcji Przeglqdu Antropologicznego byl Poznań. Przeglqd Antropologiczny ukazal się $w 1926$ roku jako dodatek do Nowin Lekarskich. W 1933 roku zrealizowano reformę wydawnictwa, które stalo się i do dziś pozostaje organem PTA oraz wszystkich zakładów antropologii w kraju. Adam Wrzosek wniósl w redagowanie Przeglqdu nie tylko wiele wysilku, ale i sporo wlasnych wkladów finansowych. Do chwili wybuchu drugiej wojny swiatowej ukazalo się 12 pelnych tomów, zas tom 13 ukazal się częściowo (zeszyt drugi) już po wojnie, w 1947 roku.

PTA bylo inicjatorem utworzenia muzeum antropologiczno-prahistoryczno-etnologicznego im. Heliodora Swięcickiego, którego pozostalości zostały po wojnie oddane $w$ formie depozytu Ministerstwu Oswiaty. Towarzystwo raz jeszcze w latach sześćdziesiątych występowalo $z$ inicjatywą utworzenia Państwowego Muzeum Antropologicznego jako centralnej placówki naukowej tego typu w kraju. W Poznaniu natomiast prof. prof. M. Godycki i F. Wokroj czynili starania o utworzenie przy Zakładzie Antropologii "Muzeum Czlowieka".

W okres powojenny, towarzystwo weszlo z ogromnymi stratami kadrowymi i materialowymi. Panujące podówczas w biologiipolskiej zapożyczone blędne teorie nie sprzyjaly rozwojowi wielu tradycyjnych kierunków badawczych polskiej antropologii, którym zarzucano m.in. determinizm i fatalizm rasowy. Konieczne stalo się nie tylko przebudowanie problematyki badawczej, ale również struktur organizacyjnych antropologii. Jednakże dośc szybko nastąpila odbudowa antropologii ze strat wojennych i przywrócone zostalo jej międzynarodowe znaczenie.

Po wojnie, po utworzeniu Polskiej Akademii Nauk, z PTA zostal wyloniony Komitet Antropologiczny. W latach 1955-1957 PTA wlączylo się do organizacji zdjęcia antropologicznego ludności Polski dla celów standaryzacjiwyrobów przemyslowych. Dużym osiągnięciem o charakterze międzynarodowym bylo zorganizowanie przez PTA i Egipską Akademię Nauk dwóch wypraw naukowych do Egiptu w latach 1958/59 i w 1962 roku oraz opublikowanie wyników badań $w$ specjalnym wydawnictwie [DZIERZYYKRAY-ROGALSKI 1959].

PTA zintensyfikowalo swą dzialalnosć. Regularnie co 3 lata odbywają się zjazdy i walne zgromadzenia. Prócz tego organizowane byly liczne ogólnopolskie konferencje naukowe, m.in. na tematy metodologiczne, typologiczne, ontogenetyczne, etnogenetyczne, afrykanistyczne, poświęcone ocenie stanu antropologii i jej dorobkowi w PRL, dydaktyce itd. PTA zorganizowalo również, wspólnie z Międzynarodowym Programem Biologicznym (IBP),w 1968 roku w Warszawie międzynarodową 
konferencję na temat "Polskie badania antropologiczne w Afryce oraz biologia czlowieka w Afryce". Od 1948 roku PTA należy do Międzynarodowej Unii Nauk Antropologicznych i Etnologicznych (IUAES) biorąc udzial $w$ kongresach i Radzie Stalej Unii. Jest członkiem Międzynarodowego Towarzystwa Biologii Czlowieka. W latach 1958-64 towarzystwo utworzylo kwartalnik popularnonaukowy Czlowiek w Czasie i Przestrzeni, którego zalożycielem i redaktorem byl prof. T. DZIERŻYKRAY-ROGALSKI. Do likwidacji kwartalnika ukazało się 25 zeszytów tego pożytecznego czasopisma. W 1975 roku z okazji jubileuszu 50-lecia Polskiego Towarzystwa Antropologicznego odbyl się Jubileuszowy Zjazd w Poznaniu, zaś towarzystwo $z$ tej okazji zostalo wyróżnione odznaczeniem przyznanym na wniosek Ministerstwa Oświaty, a mianowicie Medalem Komisji Edukacji Narodowej.

Pod koniec lat pięćdziesiątych, zaczęly powstawać oddzialy PTA w: Bialymstoku, Gdańsku, Krakowie, Lublinie, Lodzi, Poznaniu, Szczecinie, Warszawie i Wroclawiu.

Liczba czlonków w poszczególnych latach byla następująca: 1925 r. - 29, 1926 r. 42, 1927 r. $-55,1928 / 29$ r. $-73,1930$ r. - 124 , 1931 r. - 131, 1932-39 r. - 140, 1946/47 r. 55,1948 r. $-73,1949$ r. $-85,1950$ r. - 101 , 1951 r. $-135,1952-55$ r. $-196,1956-59$ r. 207, 1960-65 r. - 219, 1966-68 r. - 225, od 1970 roku liczba członków PTA waha się wokól 250 osób.

Przewodniczącymi Towarzystwa byli kolejno: Adam Wrzosek (1925-1948), Michal Cwirko-Godycki (1948-1951), Jan Mydlarski (1951-1956), Tadeusz Dzierżykray-Rogalski (1956-1984), Andrzej Malinowski (od 1984 roku).

Sekretarzami PTA byli: Wlodzimierz Missiuro (1925-1927), Michal ĆwirkoGodycki (1927-1947), Franciszek Wokroj
(1947-1951), Stanislaw Górny (19511956), Aleksander Lech Godlewski (19561960), Halina Milicerowa (1960-1963), Janusz Charzewski (1963-1975), Henryk Piechaczek (1975-1984), Piotr Lewicki (od 1984 roku).

Czlonkowie PTA dzielą się na: zwyczajnych, dożywotnich, honorowych i zasłużonych. Czlonkami honorowymi mogą być osoby, które wybitnie przyczynily się do rozwoju antropologii w Polsce lub za granicą, zaś członkami zasłużonymi - osoby zasłużone szczególnie dla rozwoju PTA i polskiej antropologii.

Godność czlonka honorowego nadano następującym uczonym:

1. 1927 rok - Julian TALKOHRYNCEWICZ (1850-1936), prof. antropologii UJ w Krakowie, dr medycyny, antropolog, historyk medycyny, etnograf;

2. 1957 rok - Božo ŠKERLJ (19041964), prof. antropologii Uniwersytetu w Lubljanie, dr biologii, antropo$\log$;

3. 1958 rok - Henri Victor VALLOIS (1889-1981), prof. anatomii i antropologii Uniwersytetu w Tuluzie, antropologii na Uniwersytecie w Paryżu i w Musee de l'Homme, dr medycyny, antropolog, anatom;

4. 1959 rok - Jan CZEKANOWSKI (1882-1965), prof. antropologii Uniwersytetu we Lwowie, Katolickiego Uniwersytetu w Lublinie i Uniwersytetu w Poznaniu, dr nauk przyrodniczych, antropolog, etnolog, slawista i statystyk, $\mathrm{dr}$ honoris causa Uniwersytetu we Wroclawiu i w Poznaniu;

5. 1959 rok - Kazimierz STOŁYHWO (1880-1966), prof. antropologii Wolnej Wszechnicy Polskiej w Warszawie, 
UJ w Krakowie, dr nauk przyrodniczych, antropolog, zoolog.

W latach 1960-1969 czlonkostwo honorowe uzyskali:

6. Robert GESSIN, prof. antropologii, dyr. Musee de l'Homme w Paryżu, dr medycyny, antropolog, demograf;

7. Olga NeCRASOVA, prof. antropologii Uniwersytetów: w Bukareszcie i w Jassy, dr nauk przyrodniczych, antropolog;

8. Ahmed Mahmoud EL Batrawi (1902-1964), prof. anatomii Uniwersytetu w Kairze, dr medycyny, antropolog, anatom;

9. Georges OliviER, prof. antropologii Uniwersytetu w Paryżu, dr medycyny, antropolog, anatom;

10. Joseph Sidney WEINER, prof. medycyny tropikalnej Uniwersytetu w Londynie, dr medycyny, antropolog; 11. Jean HIERNAUX, prof. antropologii Uniwersytetu w Brukseli i w Paryżu, dr medycyny, antropolog;

12. Paul T. BAKER, prof. socjologii i antropologii Uniwersytetu w Pensylwanii, socjolog, antropolog;

13. Wiktor W. BUNAK (1891-1979), prof. antropolofii Uniwersytetu (MGU) i Instytutu Etnografii AN ZSRR w Moskwie, dr nauk przyrodniczych, antropolog;

14. TadeusZ DZIERŻYKRAJROGALSKI, prof. antropologii UMCS w Lublinie, AWF i PAN w Warszawie, prof. anatomii prawidlowej AM W Bialymstoku, dr medycyny, mgr biologii, antropolog, anatom, demograf.

W latach 1971-1975 czlonkostwo honorowe uzyskali:

15. Jaroslav SUCHY (1926-1975), prof. antropologii Uniwersytetu w Pradze, dr nauk przyrodniczych, antropolog; 16. Jindr̃ ich VALŠIK (1903-1977), prof. pediatrii Uniwersytetu w Brnie, antropologii Uniwersytetu w Bratyslawie, dr nauk przyrodniczych, dr medycyny, antropolog, pediatra;

17. R. Ola OJIKUTU, prof. Uniwersytetu w Lagos (Nigeria), dr etnologii; 18. Aleksander Lech GoDLEWSKI (1905-1975), prof. antropologii, Uniwersytetu w Warszawie, WSWF we Wroclawiu, prof. etnografii Uniwersytetu Wroclawskiego, dr biologii, anatom porównawczy, antropolog, etnolog;

19. Bronislaw JASICKI, prof. antropologii UJ w Krakowie, dr biologii, antropolog;

20. Wieslaw KASIŃSKI, prof. anatomii prawidłowej AM w Gdańsku i Wojskowej Akademii Medycznej w Lodzi, dr medycyny, anatom, antropolog;

21. Wanda STĘŚLICKA-MYDLARSKA, prof. antropologii Uniwersytetu Wroclawskiego, Toruńskiego, WSWF we Wroclawiu, mgr filozofii, dr nauk przyrodniczych, antropolog, anatom porównawczy, prymatolog;

22. Halina MILICER, prof. antropologii AWF w Warszawie, PAN we Wroclawiu, dr wychowania fizycznego, antropolog;

23. Pawel SIKORA, prof. antropologii UJ w Krakowie, dr biologii, antropolog; 24. Stanislaw GÓRNY, doc. antropologii PAN we Wrockawiu, dr wychowania fizycznego, antropolog; 25. Carl Herman HJORTSJÖ, prof. anatomii prawidlowej Uniwersytetu w Lund, dr medycyny, anatom;

26. Wsiewolod P. JAKIMOV (19121981), prof. antropologii, dyrektor Instytutu Antropologii MGU w Moskwie, dr nauk przyrodniczych, antropolog, anatom porównawczy, prymatolog. 
W 1984 roku godnosć tę otrzymali: 27. Ilse SCHWIDETZKY, prof. antropologii Uniwersytetu w Moguncji, dr nauk przyrodniczych, antropolog; 28. Petar VLAHOVIĆ, prof. etnologii i antropologii Uniwersytetu w Belgradzie, dr etnologii;

29. Eugen STrouhal z Muzeum Narodowego w Pradze, dr medycyny, dr filozofii, antropolog;

30. Robert MALINA, prof. Uniwersytetu w Austin w Teksasie, dr n. wych. fiz., antropolog;

31. Witold HENSEL, dr nauk historycznych, prof. archeologii Uniwersytetu Poznańskiego i Warszawskiego, PAN, archeolog;

32. Franciszek WoKROJ, prof. antropologii Uniwersytetu im. A. Mickiewicza w Poznaniu, UMK w Toruniu, Uniwersytetu w Kodzi, dr nauk przyrodniczych, antropolog;

33. Paule POSENER-KRIÉGER, Francja.

Godność czlonka zaslużonego PTA otrzymali:

1. Adam WRZOSEK (1875-1965) w 1959 roku, prof. patologii, historii medycyny, antropologii UJ w Krakowie, Uniwersytecie Warszawskim i Poznańskim oraz Tajnym Uniwersytecie Ziem Zachodnich (w latach 1942-1944). Zaslugi naukowe Adama Wrzoska są ogromne, a dorobek obejmuje okolo 450 prac. Większość z nich dotyczy historii medycyny i antropologii, historii kultury, etnografii, patologii doświadczalnej. Wymienić trzeba ważniejsze monografie o: J. Śniadeckim (1910), L. Bierkowskim (1911), K. Marcinkowskim (1969/61), T. Chalubińskim (1970) i Bibliografię antropologii polskiej (1960). Nauka polska wyróżnila zasługi A. Wrzoska powolując go na czlonka zwyczajnego PAN i nadając mu godność doktora honoris causa Uniwersytetu Stefana Batoregow Wilnie (1929 rok), Akademii Medycznej w Poznaniu (1962 rok) i Uniwersytetu Jagiellońskiego w Krakowie (1964 rok).

2. Michal CWIRKO-GODYCKI (19011980) w 1969 roku, dr nauk medycznych, prof. antropologii Uniwersytetu im. A. Mickiewicza w Poznaniu i WSWF w Poznaniu. Dorobek naukowy liczy okolo 170 prac $z$ antropologii, historii medycyny i antropologii, prahistorii, wychowania fizycznego, medycyny sądowej i higieny. Na szczególną uwagę zasługują obszerne monografie: Slowianie poludniowi (1931), I. Kopernicki (1948), Życie $i$ działalnośc Teofila Chudzińskiego (1959) oraz podręczniki: Zarys antropometrii (1933, 1952, 1966), Antropologia dla studiujacych wychowanie fizyczne (1955 i wsp. z Z. Drozdowskim 1967, 1972, 1976), Higiena w zakresie studiów wychowania fizycznego (1965, 1968). Za dzialalność naukową, AWF w Poznaniu nadala mu w 1974 roku godność doktora honoris causa.

Struktura organizacyjna towarzystwa jest następująca: walne zgromadzenie, zarząd glówny, komisja rewizyjna, sąd koleżeński, zarządy oddzialów.

Bibilioteka towarzystwa znajduje się w Poznaniu, na terenie Zakladu Antropologii Uniwersytetu im. A. Mickiewicza i liczy okolo 5,5 tys. tomów wydawnictw ciąglych oraz okolo 300 książek i monografii. Księgozbiór pochodzi glów’nie z wymiany i sporadycznie $z$ darowizn. Wydawnictwa $z$ dokonywanej $w$ latach 1952-56 
wymiany zostaly wlączone do Biblioteki Zakladu Antropologii PAN we Wroclawiu. Obecnie biblioteka PTA otrzymuje z wymiany 132 tytuły czasopism. Czasopisma te mają charakter glównie antropologiczny, ale również przyrodniczy, medyczny, archeologiczny, etnologiczny itp.

Antropologia polska mimo licznych niedostatków i braków (np. instrumentarium, czasopism zagranicznych, nieobecność placówek antropologicznych w kilku uniwersytetach i innych uczelniach) nadal zajmuje czolową pozycję w świecie. Dzieje się tak dlatego, iż wysoki jest poziom tradycyjnych kierunków badawczych oraz nastąpilo włączenie się jej w nowsze kierunki oparte na genetyce, ekologii i biologii ewolucyjnej. Duże możliwości nadal leżą w związkach antropologii $z$ naukami humanistycznymi oraz stosowanymi.

Polskie Towarzystwo Antropologiczne winno więc $w$ przyszłości szerzej penetrować pokrewne antropologii środowiska naukowe, pozyskiwać z tych środowisk czlonków oraz inspiracje do dalszego rozwoju. $\mathrm{Z}$ tego co powiedziano wynika zatem ogrom zagadnień i bogactwo problemów, jakie są do rozwiązania przed antropologią końca XX w. Myślę że u progu XXI stulecia antropologia jest dużą galęzią wiedzy rozpatrującą czlowieka wielostronnie zarówno od strony jego biologii, jak i zjawisk psychicznych, kulturowych czy społecznych.

\section{Piśmiennictwo}

ABRAMOWICZ A., 1975, Société d'Anthropologie et d'Einographie Polonaise de Paris (1878-?), Kwart Hist. Nauki i Techniki., 20, 1, 79.

DZIERŻYKRAY-ROGALSKI T., 1959, Polskie Towarzys two Antropologiczne w latach 1956-59, Czlowiek w Czasie i Przestrzeni, 2, 4, 210.

GODYCKI M., 1958, Polskie Towarzystwo Antropologiczne w $X I X w$. naemigracji, Czlowiek w Czasie i Przestrzeni, 1, 3, 146.

MALINOWSKI A, 1985, Polskie Towarzystwo Antropologiczne, Oddział Poznański, Dzieje Naukowych To warzystw Medycznych w Poznaniu w latach 18321983, Poznañ, 43.

Referat wygloszony na Konferencji Antropologicznej w Błażejewku, we wrześniu 1985 r.

The article discusses the history of the Polish Anthropological Society. The development of anthropology which took place in Poland at the turn of the 19th century, particularly the activity of Józef Majer and Izydor Kopernicki contributed to the development of numerous Chairs of Anthropology at Universities. The second trend of the development of this science was the activity of the Polish emigrants, particularly in France. On their initiative, already in 1878 in Paris, a Polish Anthropological and Ethnografical Society was established with which Teofil Chudziński was associated. After the first world war anthropological institutions were created at universities which were staffed by known researchers like Jan Czekanowski (Lvov), Kazimierz Stołyhwo, Edward Loth, Jan Mydlarski (Warsaw), Julian Talko-Hryncewicz (Cracow), Michal Reicher (Vilna) and Adam Wrzosek (Poznań). The idea to create the Anthropological Society and its organ which was the "Anthropological Review" was the work of Adam Wrzosek who saw the necessity to integrate the rather scientifically differentiated anthropological circle. The Society was created in 1925 in Poznan and here were its Headquarters until the second world war. The Presidents of the Society were successively: A. Wrzosek, M. Ćwirko-Godycki, J. Mydlarski, T. Dzierzykray-Rogalski and at present this position is held by A. Malinowski. The Society integrates the Polish anthropology by its publications and the organization of scientific congresses and conferences. 